\title{
Biliary Lithiasis and Subclinical Hypothyroidism: Myth or Truth?
}

ISSN: 2637-7632

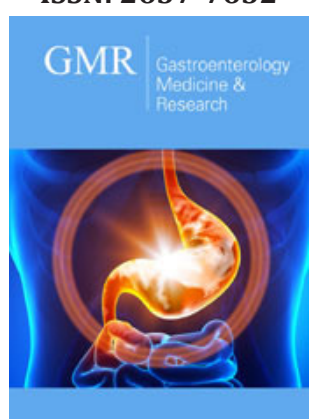

*Corresponding author: Salem Bouomrani, Department of Internal medicine, Military Hospital of Gabes, Gabes 6000, Tunisia

Submission: 海 June 26, 2020

Published: 此 December 14, 2021

Volume 6 - Issue 3

How to cite this article: Salem Bouomrani. Biliary Lithiasis and Subclinical Hypothyroidism: Myth or Truth?. Gastro Med Res. 6(3). GMR. 000638. 2021.

DOI: $10.31031 /$ GMR.2021.06.000638

Copyright@ Salem Bouomrani, This article is distributed under the terms of the Creative Commons Attribution 4.0 International License, which permits unrestricted use and redistribution provided that the original author and source are credited.

\author{
Salem Bouomrani ${ }^{1,2 *}$ \\ ${ }^{1}$ Department of Internal medicine, Military Hospital of Gabes, Tunisia \\ ${ }^{2}$ Sfax Faculty of Medicine, University of Sfax, Tunisia
}

\begin{abstract}
With an average prevalence in the general population at $4-15 \%$ and more than $20 \%$ in the elderly, Subclinical Hypothyroidism (SCH) is the most common thyroid dysfunction. The clinical and biological impact of $\mathrm{SCH}$ is sometimes atypical, unusual, and very challenging in current medical practice. Among these atypical manifestations of $\mathrm{SCH}$, some publications have suspected a particularly promoting role in the genesis of biliary lithiasis. The purpose of this review is to clarify the relationship between this thyroid dysfunction and gallstones. The systematic review of the literature allows us to conclude that the association between biliary lithiasis and SCH is far from mere chance. Diminished bile secretion, decreased liver cholesterol metabolism, and reduced sphincter of Oddi relaxation are the mechanisms involved in the formation and accumulation of biliary stones in subjects with $\mathrm{S} \mathrm{CH}$. Thus systematic screening for SCH is highly recommended in any patient diagnosed with biliary lithiasis.
\end{abstract}

Keywords: Biliary lithiasis; Subclinical hypothyroidism; Common bile duct stone; Gallstone; Hypothyroidism

\section{Introduction}

Subclinical Hypothyroidism (SCH) is the most common thyroid dysfunction [1-3]. Its prevalence in the general population is estimated on average at 4-15\% [3] but can reach more than $20 \%$ in the elderly [3]. It is far more common than overt hypothyroidism, but often remains underdiagnosed and unrecognized [1-3]. In fact, the American national survey estimated the frequency of subclinical hypothyroidism at $4.3 \%$ of the general population against only $0.3 \%$ for overt hypothyroidism [4]. Subclinical hypothyroidism is defined as the elevation of the thyroid-stimulating hormone (TSH) in plasma with normal levels of thyroid hormones (triiodothyronine (T3) and free total thyroxine (fT4)). Clinical manifestations related to the deficit of thyroid hormones are, by definition, absent during this dysthyroidism [1-3]. However, there are some controversies regarding the clinical presentations of subclinical hypothyroidism [3]. Indeed, it was noted that by applying the Billewiez-Zulewski scale which groups together the specific clinical signs of hypothyroidism (the total score goes from 0: no clinical sign is present, to 12: all clinical signs are present), a positive score between 3 and 5 was noted in all patients diagnosed with SCH [5]. This variability in the possible clinical presentations of subclinical hypothyroidism can be explained by the existence of an individual "set-point" of TSH; the interindividual variability of which would explain the great clinical polymorphism in patients with the same TSH value $[3,6]$. The clinical and biological impact of SCH is sometimes atypical, unusual, and very challenging in current medical practice [7-9]. Some publications have suspected a promoting role of SCH in the genesis of biliary lithiasis [10-13]. The purpose of this review is to clarify the relationship between this thyroid dysfunction and gallstones. 


\section{Biliary stones in SCH}

Hypothyroidism is currently recognized as a risk factor for biliary lithiasis, whether gallstone's or of the common bile duct (CBD) [10-12]. Indeed, in Ahmad MM [13] series, hypothyroidism was noted in $16 \%$ of patients with choledocholithiasis and in $8 \%$ of patients with cholelithiasis [13]. Similarly, Laukkarrien et al, in their large study found a prevalence of hypothyroidism (both overt and subclinical) of $10.2 \%$ in patients with common bile duct stone [11]. Inkinen et al. [10] demonstrated this association between hypothyroidism and biliary lithiasis by revealing a statistically higher prevalence of primary hypothyroidism in patient with choledocholithiasis compared to healthy control group: $8 \%$ Vs $1 \%$, $\mathrm{p}<0.01[10]$.

\section{Mechanisms of hypothyroidism-associated biliary stones}

The biliary lithogenesis during primary hypothyroidism goes through several pathogenic mechanisms, namely the decrease in the hepatic metabolism of cholesterol which will accumulate in the bile making it saturated and thick [14], the decrease in the hepatic clearance of bile [15] and the reduced sphincter of Oddi relaxation [16,17]. Taken together, these factors make biliary lithiasis significantly frequent in hypothyroid patients compared to the general population: $11 \%$ versus $2 \%$ according to Laukkarinen J [18] study. All these mechanisms promoting biliary lithogenesis during overt hypothyroidism have also been validated in subjects with $\mathrm{SCH}$, justifying that $75 \%$ of patients with hypothyroidismassociated biliary lithiasis was diagnosed as having subclinical forms of this endocrinopathy in Ahmed MM et al series [13].

\section{Biliary stones in subclinical hypothyroidism}

Association between biliary lithiasis and subclinical hypothyroidism was noted in several studies and in several populations [10-18]. Laukkarinen J et al. [12], in their Finnish prospective study, objectified a statistically significant prevalence of common bile duct stone in patients with SCH compared to the general euthyroid population: $5.3 \%$ Vs $1.4 \%$. This difference was much more marked in women older than 60 year: $11.4 \%$ Vs $1.8 \%$ [11]. Rassam Ghadhban B \& Najim Abid F [19] cross-sectional study regrouping 103 Iraqi patients with gallstones, objectified eight with SCH (7.8\%) [19]. Moreover, 75\% of patients with biliary stone and SCH had positive family history of cholelithiasis [19]. Ajdarkosh $\mathrm{H}$ [20] study evaluating thyroid function pattern in 151 patients with common bile duct stones, objectified SCH in $30.6 \%$ of them contrary to only $22.5 \%$ of cases in the healthy individuals control group [20]. They also noted a mean serum TSH levels statistically higher among patients with CBD stone than controls $(2.79 \pm 4.86$ Vs $2.03 \pm 4.13$; $\mathrm{p}=0.01$ ), with a statistically significant difference between the two groups to be at risk for SCH; thus they concluded that SCH could be a risk factor for the development of CBD stones [20]. The association between SCH and biliary stone seems to be statistically increasing among females over 40 years, patients with positive family history of cholelithiasis, and patients with single gall stone on abdominal ultrasound $[11,17,19,20]$. Similarly, choledocholithiasis is more prevalent in females with SCH $[13,19,20]$. Thus, some authors recommend systemic screening of thyroid function in any patient with gallstones' or common bile duct stone, even in the absence of any symptom or sign of hypothyroidism. This screening is all the more recommended whether it is female or elderly $[11,17,18]$.

\section{Conclusion}

The association between biliary lithiasis and subclinical hypothyroidism seems to be far from mere chance. Subjects with this thyroid dysfunction appear to have a significantly increased risk of developing gallbladder stones and common bile duct lithiasis. This risk is particularly increased in women and the elderly. Thus systematic screening for SCH is highly recommended in any patient diagnosed with biliary lithiasis.

\section{References}

1. Khan SH, Ijaz A (2019) Subclinical-hypothyroidism: A pathology in evolution. J Coll Physicians Surg Pak 29(2): 150-158.

2. Dolgikh YA, Verbovoy AF, Sharonova LA (2017) Subclinical hypothyroidism. Klin Med (Mosk) 95(2): 118-22.

3. Bouomrani S (2020) Subclinical hypothyroidism: The neglected thyroid dysfunction (Review). EC Endocrinology and Metabolic Research 5(5): 23-30.

4. Nabhan F, Porter K, Kloos RT (2013) Predicting hypothyroidism from the whickham survey. Clin Endocrinol (Oxf) 78(3): 478.

5. Zulewski H, Muller B, Exer P, Miserez AR, Miserez AR, Staub JJ (1997) Estimation of tissue hypothyroidism by a new clinical score: Evaluation of patients with various grades of hypothyroidism and controls. J Clin Endocrinol Metab 82(3): 771-776.

6. Fatourechi V (2009) Subclinical hypothyroidism: an update for primary care physicians. Mayo Clin Proc 84(1): 65-71.

7. Bouomrani S, Ben Khalifa A (2020) Resistant hypertension: Don't forget subclinical hypothyroidism. EC Cardiology 7(3): 01-03.

8. Bouomrani S, Masmoudi I (2020) Neuropsychiatric involvement in subclinical hypothyroidism. Arch Neurol \& Neurosci 7(5): 1-4.

9. Bouomrani S, Rgaïeg N (2019) Isolated non-autoimmune neutropenia revealing primary hypothyroidism. Blood Heart Circ 3: 1-3.

10. Inkinen J, Sand J, Nordback I (2000) Association between common bile duct stones and treated hypothyroidism. Hepato-Gastroenterology 47(34): 919-21.

11. Laukkarinen J, Kiudelis G, Lempinen M, Räty S, Pelli H, et al. (2007) Increased prevalence of subclinical hypothyroidism in common bile duct stone patients. J Clin Endocrinol Metab 92(11): 4260-4264.

12. Laukkarinen J, Sand J, Autio V, Nordback I (2010) Bile duct stone procedures are more frequent in patients with hypothyroidism. A large, registry-based, cohort study in Finland. Scand J Gastroenterol 45(1): 7074.

13. Ahmad MM, Irfan NM, Mohamed DH (2015) Evaluation of thyroid profile in biliary tract stones. Int Surg J 2(3): 344-347.

14. Andreini JP, Prigge WF, Ma C, Gebhard RL (1994) Vesicles and mixed micelles in hypothyroid rat bile before and after thyroid hormone treatment: Evidence for a vesicle transport system for biliary cholesterol secretion. Journal of Lipid Research 35(8): 1405-1412.

15. Field FJ, Albright E, Mathur SN (1986) Effect of dietary cholesterol on biliary cholesterol content and bile flow in the hypothyroid rat. Gastroenterology 91(2): 297-304. 
16. Inkinen J, Sand J, Arvola P, Pörsti I, Nordback I (2001) Direct effect of thyroxine on pig sphincter of oddi contractility. Dig Dis Sci 46(1): 182186.

17. Laukkarinen J, Sand J, Aittomäki S (2002) Mechanism of the prorelaxing effect of thyroxine on the sphincter of Oddi. Scandinavian Journal of Gastroenterology 37(6): 667-673.

18. Laukkarinen J, Sand J, Nordback I (2012) The underlying mechanisms: How hypothyroidism affects the formation of common bile duct stones-a review. HPB Surg, pp.102825.
19. Rassam Ghadhban B, Najim Abid F (2018) The prevalence and correlation between subclinical hypothyroidism and gall stone disease in Baghdad teaching hospital. Ann Med Surg (Lond) 37: 7-10.

20. Ajdarkosh H, Khansari MR, Sohrabi MR, Hemasi GR, Shamspour N, et al. (2013) Thyroid dysfunction and choleduocholithiasis. Middle East J Dig Dis 5(3): 141-145.

For possible submissions Click below: 